\title{
Abusive supervision and links to nurse intentions to quit
}

\section{Abstract}

Purpose: To investigate forms of abusive supervision, namely personal attacks, task attacks and isolation, and their links to outcomes for nurses, including job satisfaction, psychological strain and intentions to quit.

Design: Cross-sectional survey design. Data collected from July to November 2012.

Methods: Two hundred and fifty public sector nurses employed at five general acute Australian hospitals completed the survey (response rate of 33\%).

Findings: Structural equation modeling on the forms of abusive supervision (personal, task, isolation) and nurse outcomes indicated goodness of fit statistics that confirmed a well-fitting model, explaining $40 \%$ of the variance in intent to quit, $30 \%$ in job satisfaction and $33 \%$ in strain. An indirect relationship from personal attacks to intentions to quit, via strain, was observed. Task attacks were related directly, and indirectly via job satisfaction, to increased intentions to quit. Surprisingly, isolation was positively related to job satisfaction.

Conclusions: Abusive supervision impacted nurse outcomes. Specifically, personal abuse had personal and health impacts; work-focused abuse had work-oriented effects. Applying appraisal theory suggests that personal attacks are primarily assessed as stressful and unchangeable, task-oriented attacks are assessed as stressful, but changeable, and isolation is assessed as benign. The findings highlight the impact of abusive supervision, especially taskattacks, on outcomes important to nurse retention.

Clinical Relevance: The findings can be used to devise programs to educate, train and support supervisors and their subordinates to adhere to zero tolerance policies toward antisocial workplace behaviors and encourage reporting incidents.

Keywords: Abusive supervision, cognitive appraisals, intent to quit, job satisfaction, stress 


\section{Introduction}

Nurses are a high risk occupational group for a range of anti-social behaviors in the workplace (e.g., Hegney, Plank, \& Parker, 2003; Quine, 2001). Despite being considered a substantial issue in many organisations (Tepper, 2000), much of the research on hostile workplace behavior has focused on anti-social behaviors from co-workers (e.g., McKenna, Smith, Poole, \& Coverdale, 2003) or aggression from those external to the organisation (e.g., Demir \& Rodwell, 2012; Duxbury \& Whittington, 2005), with few studies specifically focusing on abusive supervision (cf Tepper, Moss, Lockhart, \& Carr, 2007).

Abusive supervision refers to subordinates' perceptions of their supervisor's display of sustained verbal or nonverbal hostile behavior, such as intimidation through the use of threats, invasion of privacy or humiliation (Tepper, 2000). Research in this area has examined abusive supervision consisting of personal attacks, demonstrating that these attacks lead to reduced job satisfaction, as well as increased psychological strain and intent to quit (e.g., Bowling \& Michel, 2011; Tepper et al., 2009; Tepper, Duffy, Hoobler, \& Ensley, 2004). Little attention in abusive supervision research is paid to other behaviors related to employee work tasks (e.g. excessively monitoring work tasks or being allocated meaningless tasks), which are assessed in the closely-related and overlapping constructs of petty tyranny (Ashforth, 1994, 1997) and supervisor undermining (Duffy, Ganster, \& Pagon, 2002). There is also a lack of research examining the consequences of different forms of abusive supervision. Therefore, the aim of this study is to investigate a wider range of forms of abusive supervision, particularly those involving task attacks, personal attacks or a combination of these, such as isolating behaviors, and how different forms of abusive supervision might be linked to different work and health outcomes for nurses.

\section{Background}


Most of the acts that currently fall within the domain of abusive supervision focus on personal attack behaviors, such as displays of ridicule, negative comments, rudeness and lies (Tepper, 2000), with little focus on abusive supervision targeted toward an employee's work tasks. In comparison, the construct of petty tyranny is based on the use of power and authority by managers in a manner that is oppressive, capricious and vindictive (Ashforth, 1994, 1997). Abusive supervision differs from petty tyranny in that petty tyranny can include both hostile and non-hostile behaviors (Tepper, 2007). Petty tyranny includes tyrannical behaviors related to work that can be considered hostile and overlap with abusive supervision (Tepper, 2007), such as the supervisor being critical of the employee's work even when they perform well, or the supervisor being displeased with the employee's work for no apparent reason (Ashforth, 1994). Similarly, task-oriented behaviors that comprise supervisor undermining include hindering work success such as where the supervisor undermines the employee's efforts to be successful on the job, or delays work to make the employee look bad (Duffy et al., 2002). However, such task-oriented behaviors are rarely examined within the domain of abusive supervision.

Moreover, there are other types of abusive supervision behaviors that may be less distinguishable as either person-oriented or task-oriented, but could be viewed as a combination. For example, Tepper (2000) describes abusive supervision behaviors as those that appear to isolate the subordinate, such as their supervisor giving them the silent treatment, or not allowing them to interact with coworkers. These isolating acts could be considered a combination of personal- and task-related attacks.

The potential mechanisms involved in the links between forms of abusive supervision and employee health and work outcomes may be drawn from Lazarus and colleagues' theory on stress, appraisals and coping (Folkman, Lazarus, Dunkel-Schetter, DeLongis, \& Gruen, 1986; Lazarus, DeLongis, Folkman, \& Gruen, 1985; Lazarus \& Folkman, 1984). According 
to their appraisal theory, cognitive appraisal processes and coping are major mediating processes in the relationship between a stressful person-environment encounter and immediate and long-term outcomes. Cognitive appraisal is the process where a person evaluates whether an encounter with the environment is relevant to their wellbeing (i.e. primary appraisal) and, if so, there is an evaluation of what can be done about the encounter (i.e. secondary appraisal). Encounters can be distinguished in three ways: irrelevant, benignpositive or stressful (Lazarus \& Folkman, 1984). When an encounter has no implications for a person's wellbeing, the encounter is viewed as irrelevant. Benign-positive appraisals tend to occur if the encounter is interpreted as positive and may enhance a person's wellbeing. Stress encounters can include harm/loss, threat and/or challenge.

During the appraisal process, the coping options available are evaluated. There are two well-known types of coping: emotion- and problem-focused (Folkman et al., 1986; Lazarus \& Folkman, 1984). Emotion-focused coping functions by regulating stressful emotions. Examples include positive reappraisal (i.e. efforts of focusing on positive meaning via personal growth) and distancing (i.e. efforts to detach and potentially create a positive outlook). In contrast, problem-focused coping functions by altering the person-environment encounter causing a problem. Examples of problem-focused coping can include planful problem-solving (e.g. focusing efforts on solving the problem by using an analytical approach) and escape-avoidance (e.g. efforts surrounding wishful thinking that the problem would disappear and behaviorally escaping or avoiding the problem). There is a complex interplay between primary and secondary appraisals that can impact the extent to which an emotional reaction is stressful and the quality (or content) of the reaction. For example, per appraisal theory, some appraisals can include evaluations of the extent to which an encounter is changeable, targeting personal vulnerabilities (e.g. self-esteem) or less personal stakes (e.g. work-related), which may lead to different outcomes (Folkman et al., 1986). 
Applying these forms of appraisal to abusive supervision delineates the more commonly-examined personal form of abusive supervision as being primarily appraised as stressful and unchangeable, targeting personal vulnerabilities and being more likely to be internalised (per Folkman et al., 1986). Task-oriented attacks (e.g., Duffy et al., 2002) that intend, but do not do, immediate harm are a form of abusive supervision (Tepper, 2007) that would be appraised as stressful, but changeable. It is less clear how the alternative, isolation, form of abusive supervision would be appraised. Isolation could be appraised as being irrelevant, or stressful, but it could be assessed as benign, and the delineation of how it is appraised may need to be deduced from the consequences isolation has on the employee.

Most of the research on the consequences of abusive supervision has focused on the personal attacks form of abusive supervision, particularly using Tepper's (2000) measure, showing links with various work and health outcomes. For instance, several studies have found relationships between this form of abusive supervision and reduced job satisfaction (Tepper, 2000; Tepper et al., 2004), increased psychological strain or distress (Tepper et al., 2007), decreased psychological health (Bowling \& Michel, 2011), as well as increased intent to quit (Tepper et al., 2009), among other negative consequences. To the best of the authors' knowledge, no studies have examined the separate outcomes of different forms of abusive supervision. In the context of these previously-found links for overall abusive supervision, with a focus on personal attacks on to negative outcomes, this study extends that work by investigating which outcomes are related to which specific form(s) of abusive supervision.

The primary aim of this study is to examine forms of abusive supervision, namely personal attacks, task attacks and isolation, and their links to work and health outcomes for nurses, including job satisfaction, psychological strain and intentions to quit. Figure 1 below illustrates these theoretically-proposed links, in terms of their most likely path of impact, via the stress appraisals and coping processes suggested. Based on the previous research on 
abusive supervision, as well as appraisal theory, the following hypotheses are proposed. Hypothesis 1: Personal attacks of abusive supervision (e.g. receiving persistent criticism) will be linked directly and indirectly to the health-related outcomes of increased psychological strain and increased intentions to quit. Hypothesis 2: Task attacks of abusive supervision (e.g. excessive monitoring of work) will be linked directly and indirectly to the work-related outcomes of decreased job satisfaction and increased intentions to quit. Hypothesis 3: Isolating behaviors will be linked directly and indirectly to the work and health outcomes of decreased job satisfaction, increased psychological strain and increased intentions to quit.

(Figure 1 goes about here)

\section{Methods}

\section{Design and procedure}

The surveys were distributed to all of the nurses working in the general and surgical wards across the participating network hospitals. Participation was both voluntary and anonymous, and no incentives were offered for participation. The paper-based surveys were distributed by the researchers at each of the participating wards, and at various timed during the day to capture nurses from different shifts. The researchers returned on several occasions over a period of 2 weeks to collect the surveys. The survey period was from July to November 2012.

\section{Participants}

The study sample comprised 250 public sector nurses employed at five general acute Australian hospitals within the same local network. The hospitals were selected because they were convenient and offered a mix of sizes. One from the network was omitted due to distance (more than 150 kilometres) from the researchers. The geographic area was large, covering rural and city hospitals, but not remote. 
The hospitals covered services of emergency, general medicine and surgery (including subspecialties), obstetrics, aged care and mental health. Seven hundred and fifty nurses were invited to participate in the survey, reflecting a response rate of $33 \%$. The sample included a range of nursing jobs, including nurse managers, but were primarily staff nurses. We combined all these nurses because they all undertake similar tasks. All nurses would similar tasks to a varying degree in terms of accessing information to effectively carry out their clinical activities. The respondents were mostly female (83.2\%) and most were aged between 41 and 60 years $(64.8 \%)$, representing the nursing population where $91 \%$ are female, $40 \%$ are aged 45 years or older and nearly $90 \%$ are qualified nursing professionals (ABS 2005). Most had worked in their current job for four to five years, usually reporting a total work week of 40 hours or more $(81.2 \%)$. The proportions of the sample by education level were postgraduate $(20.8 \%)$, undergraduate $(38.8 \%)$ and diploma/certificate studies $(14.8 \%)$, with the remainder of the sample specifying 'other' $(25.6 \%)$. Feedback from staff at the hospitals suggested that the 'other' category may represent older nurses who completed hospital training before the requirement of post-school qualifications was introduced. Older nurses completing a degree later in their career may therefore consider themselves hospital trained and select 'other' as a result.

\section{Measures}

Abusive supervision and the behaviors incorporated therein were measured using an adapted version of Dick and Rayner's (2004) measure. This measure was used as a starting point to assess a wider breadth of abusive supervision. There were three subscales prefaced with a request to rate items in relation to the employee's supervisor: task attacks (4 items, e.g. 'I am given meaningless tasks'), personal attacks (4 items, e.g. 'At work, I receive persistent 
criticism), and isolation ( 2 items, e.g. 'At work, I am ignored by others'). Responses were on a six-point rating from strongly agree to strongly disagree.

A shortened five-item version of Brayfield and Rothe (1951) satisfaction scale was used to measure job satisfaction. Participants rated each statement (e.g. 'I find real enjoyment in my job') on a six-point rating from strongly agree to strongly disagree. Self-perceived psychological strain or distress was measured with the Kessler-10 (K-10; Kessler \& Mroczek, 1994). Participants rated how often they experienced issues related to their health in the past 30 days (e.g. 'I feel so restless I can't sit still') using a six-point rating from strongly agree to strongly disagree. Intent to quit: Intent to quit was assessed using three sets of items to derive an eight-item comprehensive and stable measure. Three items were adapted from Meyer, Allen and Smith (1993; 'I frequently think about leaving my current employer'), another three from Chatman (1991; e.g., 'I would prefer another more ideal job than the one I have now'), and two from Landau and Hammer (1986; e.g., 'I am seriously thinking about quitting my job'), all using a six-point rating from strongly agree to strongly disagree.

\section{Data analysis and model testing}

The data were analyzed using SPSS 19 (IBM Corp., 2010) and Amos 19 (Arbuckle, 2010). Descriptive analyses were conducted to assess the degree of exposure to abusive supervision. Structural equation modeling (SEM) was undertaken to test the links between types of abusive supervision and work and health outcomes. A variety of fit indices were used, namely: (1) the chi-square statistic ratio to the degrees of freedom $\left(\chi^{2} / \mathrm{df}\right),(2)$ the Bollen-Stine bootstrap $p$ value, (3) the standardised root mean square residual (SRMR), (4) the root mean square error of approximation (RMSEA), (5) the Tucker-Lewis index (TLI) and (6) the comparative fit index (CFI). The Bollen-Stine bootstrap $p$ value provides the corrected $p$-values for the chi-square statistic to assess overall model fit and is often slightly more accurate than the re-scaled chi-square statistic (Yuan \& Bentler, 2000). Models are 
considered to fit the data well when the following criteria are met: $p>.05, \chi^{2} / \mathrm{df}<2$, SRMR $<.08$, RMSEA <.05, TLI >.95 and CFI > .95 (Hoyle, 1995).

Prior to conducting the SEM analyses, CFAs were undertaken to examine the unidimensionality and discriminant validity of the measures used. For abusive supervision, the three-factor structure had superior fit $(\mathrm{CFI}=.932$, TLI=.904, RMSEA=.106, SRMR=.080) to the global model, with high item loadings ranging from .61 to .95 . Although these statistics do not meet strict model criteria, recent literature (Marsh, Hau, \& Wen, 2004) suggests that the criteria are too stringent for measurement analyses. Therefore the three factor structure for abusive supervision was adopted and the stricter and appropriate criteria were used for the structural analyses. In relation to the other measures of the study, job satisfaction had good CFA results $(\mathrm{CFI}=.999$, TLI=.998, RMSEA $=.022$, SRMR =.0131). Regarding psychological strain and intention to quit, the CFA results were inadequate, therefore a single item from the psychological strain measure (i.e. 'I feel tired out for no good reason') and one reverse coded item from the intent to quit measure (i.e. 'If I had my way, I will be working for this organisation three years from now') were removed, resulting in improved CFA results (psychological strain: $\mathrm{CFI}=.875, \mathrm{TLI}=.833$, RMSEA $=.193$, SRMR $=.0502$; intent to quit: $\mathrm{CFI}=.921, \mathrm{TLI}=.882, \mathrm{RMSEA}=.139, \mathrm{SRMR}=.0558)$.

Single indicator latent variables (SILVs) were used for all the variables, except for the abusive supervision scale of isolation because isolation was comprised of only two items and therefore was represented in the model as a latent variable. SILVs have been found to work as well as other parceling methods (Sass \& Smith, 2006) and have become more common in published SEM analyses (e.g., Densten, 2005; Hamilton \& Tee, 2010). Mediation effects were tested per Judd and Kenny, (2010).

\section{Findings}


The frequencies of reported abusive supervision in term of degree of exposure across the different forms (i.e. personal attacks, task attacks and isolation) are provided in Table 1. A minority of the respondents indicated some level of exposure (i.e. strongly agree, agree or slightly agree) to personal attacks (11.2\%), task-related attacks $(35.6 \%)$ or isolation $(13.6 \%)$.

(Table 1 about here)

The scale means, standard deviations, Cronbach alpha coefficients and correlations are presented in Table 2. The hypothesised model was tested in Model $1\left(M_{1}\right)$ and had a $\chi^{2}(\mathrm{df})$ of 19.52(7), $p<.05$, Bollen-Stine $p>.05$, SRMR=.040, RMSEA=.085 (CI90 .04, .09), CFI=.982, TLI=.947, a difference of $\Delta \mathrm{x}^{2}(14)=704.49, \mathrm{p}<.05$ over the Null model $\left(\mathrm{M}_{0}\right)$. The non-significant paths were then removed in Model $2\left(\mathrm{M}_{2}\right)$, resulting in a $\chi^{2}(\mathrm{df})$ of $20.367(10)$, $p=.026$, Bollen-Stine $p=.570$, a difference of $\Delta \mathrm{x}^{2}(3)=.84, \mathrm{p}>.05, \mathrm{SRMR}=.039$, RMSEA=.065 (CI90 .02, .11), CFI=.985, TLI=.969. The goodness of fit statistics for each model are presented in Table 3 with $\mathrm{M}_{2}$ resulting in a good (non-significant) fit to the data.

(Table 2 about here)

Figure 2 illustrates the final structural equation model. Several direct effects between the abusive supervision forms and outcomes were observed, with the strongest between task attacks and job satisfaction (-.70), followed by personal attacks to psychological strain (.58).

(Figure 2 about here)

Indirect relationships between the abusive supervision forms and consequences were also found. Job satisfaction mediated the relationship between increased isolation and intent to quit, leading to decreased intentions. Psychological strain mediated the relationship between increased personal attacks and intent to quit, increasing quit intentions. The strongest partial mediation effect linked increased task attacks, through decreased job satisfaction, to increased intention to quit.

\section{Discussion}


This study examines the work and health outcomes of forms of abusive supervision, including personal attacks, task-related attacks and isolating behaviors with possible implications for different appraisal and coping processes. The results of the study highlight important direct and indirect relationships between the study variables. More specifically, the results reveal an indirect relationship for personal attacks with increased intentions to quit via increased psychological strain, which partly supports earlier predictions (Hypothesis 1), although the anticipated direct relationship was not observed (cf: Bowling \& Michel, 2011; Tepper et al., 2009; Tepper et al., 2007). The current study was able to go a step further and distinguish these types of abusive supervision from other types related to work task attacks, influencing different outcomes.

Applying appraisal theory, specific processes may have been involved in the links between personal attacks and health-related outcomes (Folkman et al., 1986; Lazarus et al., 1985; Lazarus \& Folkman, 1984), whereby personal attacks of abusive supervision were appraised as work-related stressors that were more personal, leading to increased psychological strain. This increased psychological strain may have then led to problemfocused coping (e.g. planful problem-solving or escape-avoidance coping) including increased intentions to leave the organisation.

In contrast, task-oriented attacks of abusive supervision were directly related to increased intentions to quit and indirectly related to intention to quit via decreased job satisfaction, as hypothesised (Hypothesis 2). These findings are somewhat in line with previous work (e.g., Bowling \& Michel, 2011; Tepper, 2000; Tepper et al., 2009; Tepper et al., 2004), that found abusive supervision to be linked to decreased job satisfaction or higher turnover intentions, albeit when abusive supervision is measured at a broad, global level. The current study was able to highlight that similar relationships were observed for abusive supervision when examined as task-related attacks. 
Taken together, and again applying appraisal theory, it appears different processes may have been involved in the links between task-related attacks and personal attacks for the work- and health-related outcomes, respectively. That is, task attacks of abusive supervision may have been appraised by nurses as work-related stressors, which are less personal, therefore leading to decreased job satisfaction and, in turn, increased intention to leave an organisation, possibly via more problem-focused coping. Thus, the results suggest that for personal attacks of abusive supervision, these behaviors may have been appraised somewhat differently, leading to different consequences.

Although the results of the study support these theoretical implications, similar processes were not observed for abusive supervision in the form of isolating behaviors. Isolation, as a separate form of abusive supervision, was found to be indirectly related to decreased intentions to quit via increased job satisfaction. This relationship was surprising, and not in line with initial predictions (Hypothesis 3). These findings also did not support previous research on abusive supervision, which has found the opposite relationship for employee outcomes of job satisfaction or turnover intentions when abusive supervision is measured as a global construct, rather than a specific form (e.g., Bowling \& Michel, 2011; Tepper, 2000; Tepper et al., 2009; Tepper et al., 2004).

There may be an alternative explanation for abusive supervision that involves isolating behaviors where the underlying appraisal process by the subordinate nurse may be appraised as being a benign-positive person-environment encounter, rather than a workplace stressor (Folkman et al., 1986; Lazarus et al., 1985; Lazarus \& Folkman, 1984). In these instances, because the nurse is not in direct contact with the abusive supervisor, their satisfaction with their job may be enhanced and any intentions to leave reduced. Further, the coping strategy adopted may differ, whereby the impact of isolation may have occurred 
because an emotion-focused coping of distancing is being utilised, where the nurse detaches from the problem and is able to make light of the isolation (Folkman et al., 1986).

The results of this study highlight key practical implications for organisations to avoid the negative consequences associated with abusive supervision that occur, not just for the nurses themselves (i.e. job satisfaction and psychological strain), but also for the organisation when increased intentions to quit are likely to be followed by actual turnover. Healthcare organisations, which typically adopt a zero tolerance policy to abusive supervision and other related behaviors, can use these findings to assist in developing programs that are aimed at educating, training and supporting supervisors and their subordinates regarding abusive supervision. Such programs could be beneficial in enhancing the knowledge and sensitivities of nurses to abusive supervision, as well as avoiding the potential consequences that can occur as a result, particularly by encouraging ways to enact the policy of the organisation. That is, there needs to be open and transparent processes for nurses to report incidents.

There are several limitations of the current study that need to be considered. A crosssectional design was adopted, restricting the ability to draw strong causal inferences. Longitudinal research is therefore encouraged in order to more confidently draw causal inferences, particularly as longitudinal studies are rarely conducted in the area of abusive supervision. Further, the response rate the study (33\%) creates issues surrounding the generalizability of the results. Future research improving the response rate would help to reduce such issues. Moreover, the direct measurement of appraisal and coping processes would have been helpful in making stronger conclusions about the underlying mechanisms of the relationships observed between abusive supervision and its consequences. By specifically testing these constructs research would be better able to determine which particular forms of abusive supervision (particularly isolation) were appraised as stressful or otherwise, and that certain types of coping strategies are more or less likely to be employed in these encounters. 
Given the lack of previous research in this area surrounding such processes, this study has provided a justification for future researchers to do so. Further, it is important to also consider other individual factors, given the inherent subjective nature of abusive supervision, such as those related to personality and dispositional affect. Finally, there are likely to be reasons for nurses quitting that are not related to abusive supervision or dissatisfaction, such as higher pay elsewhere, family moving to another location, and better development opportunities or advancement prospects elsewhere.

\section{Conclusion}

Taken together, the main results of the study highlight how different work- and health-related outcomes are linked to different forms of task- and person-oriented attacks within the domain of abusive supervision, with consequent implications for nurses' increased intentions to quit. The consequences of abusive supervision appear to primarily impact the outcomes that are most similar to the nature of the abuse, through a source- or naturematching mechanism. For example, personal abuse primarily had personal impacts, particularly on the nurse's health, and work-focused abuse had more work-oriented effects. Task attacks had both direct and indirect effects on intentions to quit. Yet, this research is not without limitations and therefore the results must be treated with some caution. Nevertheless, the results can be used to devise programs aimed at educating, training and supporting supervisors and their subordinates to help ensure adherence to zero tolerance policies toward anti-social workplace behaviors and to encourage reporting incidents.

\section{Clinical Resources}

Royal College of Nursing, Australia: http://www.rcna.org.au/wcm/

\section{References}


Arbuckle, J. (2010). AMOS (Version 19.0). Chicago: SPSS.

Ashforth, B. (1994). Petty tyranny in organizations. Human Relations, 47 (7), 755-778. doi: $10.1177 / 001872679404700701$

Ashforth, B. (1997). Petty tyranny in organizations: A preliminary examination of antecedents and consequences. Canadian Journal of Administrative Sciences, 14(2), 126-140. doi: 10.1111/j.1936-4490.1997.tb00124.x

ABS (2005) Australia's Social Trends. Paid Work: Nursing Workers. Catalogue 4102.0. Australian Bureau of Statistics, Canberra.

Bowling, N., \& Michel, J. S. (2011). Why do you treat me badly? The role of attributions regarding the cause of abuse in subordinates' responses to abusive supervision. Work \& Stress, 25(4), 309-320. doi: 10.1080/02678373.2011.634281

Brayfield, A. H., \& Rothe, H. F. (1951). An index of job satisfaction. Journal of Applied Psychology, 35(5), 307-311. doi: 10.1037/h0055617

Chatman, J. A. (1991). Matching people and organizations: Selection and socialization in public accounting firms. Administrative Science Quarterly, 36(3), 459-484. doi: 10.5465/AMBPP.1989.4980837

Demir, D., \& Rodwell, J. (2012). Psychosocial antecedents and consequences of workplace aggression for hospital nurses. Journal of Nursing Scholarship, 44(4), 376-384. doi: 10.1111/j.1547-5069.2012.01472.x

Densten, I. L. (2005). The relationship between visioning behaviours of leaders and follower burnout. British Journal of Management, 16(2), 105-118. doi: 10.1111/j.14678551.2005.00428.x

Dick, G., \& Rayner, C. (2004). Exploring the workplace bullying construct: An evidencebased approach (Vol. 51). Canterbury Business School: University of Kent.

Duffy, M. K., Ganster, D. C., \& Pagon, M. (2002). Social undermining in the workplace. Academy of Management Journal, 45(2), 331-351. doi: 10.2307/3069350 
Duxbury, J., \& Whittington, R. (2005). Causes and management of patient aggression and violence: staff and patient perspectives. Journal of Advanced Nursing, 50(5), 469-478. doi: 10.1111/j.1365-2648.2005.03426.x

Folkman, S., Lazarus, R. S., Dunkel-Schetter, C., DeLongis, A., \& Gruen, R. J. (1986). Dynamics of a stressful encounter: Cognitive appraisal, coping, and encounter outcomes. Journal of Personality and Social Psychology, 50(5), 992-1003. doi: $10.1037 / 0022-3514.50 .5 .992$

Hamilton, J., \& Tee, S. (2010). The value-expectations relationship: Connecting customerperceived value with the expectations of pharmacy-offered services. Information and Management, 47, 1-18. doi: 10.1016/j.im.2009.09.002

Hegney, D., Plank, A., \& Parker, V. (2003). Workplace violence in nursing in Queensland, Australia. International Journal of Nursing Practice, 9(4), 261-268.

Hoyle, R. (1995). Structural equation modelling: Concepts, issues, and applications. Thousand Oaks, CA: SAGE Publications.

IBM Corp. (2010). IBM SPSS Statistics for Windows, Version 19.0. Armonk, NY: Author.

Judd, C. M., \& Kenny, D. A. (2010). Data analysis in social psychology: Recent and recurring issues: John Wiley \& Sons, Inc.

Kessler, R., \& Mroczek, D. (1994). Final versions of our non-specific psychological distress scale (Vol. 10). Ann Arbor MI: Survey Research Centre of the Institute for Social Research, University of Michigan.

Landau, J., \& Hammer, T. H. (1986). Clerical employees' perceptions of intraorganizational career opportunities. Academy of Management Journal, 29(2), 385-404. doi: $10.2307 / 256194$

Lazarus, R., DeLongis, A., Folkman, S., \& Gruen, R. (1985). Stress and adaptational outcomes. American Psychologist, 40(7), 770-779. doi: 10.1037/0003-066X.40.7.770

Lazarus, R., \& Folkman, S. (1984). Stress, appraisal, and coping. New York: Springer.

Marsh, H. W., Hau, K.-T., \& Wen, Z. (2004). In search of golden rules: Comment on hypothesis-testing approaches to setting cutoff values for fit indexes and dangers in 
overgeneralizing Hu and Bentler's (1999) findings. Structural Equation Modeling, 11(3), 320-341. doi: 10.1207/s15328007sem1103_2

McKenna, B. G., Smith, N. A., Poole, S. J., \& Coverdale, J. H. (2003). Horizontal violence: Experiences of registered nurses in their first year of practice. Journal of Advanced Nursing, 42(1), 90-96.

Meyer, J. P., Allen, N. J., \& Smith, C. A. (1993). Commitment to organizations and occupations: Extension and test of a three-component conceptualization. Journal of Applied Psychology, 78(4), 538. doi: 10.1037/0021-9010.78.4.538

Quine, L. (2001). Workplace bullying in nurses. Journal of Health Psychology, 6(1), 73-84. doi: $10.1177 / 135910530100600106$

Sass, D. A., \& Smith, P. L. (2006). The effects of parceling unidimensional scales on structural parameter estimates in structural equation modeling. Structural Equation Modeling, 13(4), 566-586. doi: 10.1207/s15328007sem1304_4

Tepper, B. J. (2000). Consequences of abusive supervision. Academy of Management Journal, 43(2), 178-190. doi: 10.2307/1556375

Tepper, B. J. (2007). Abusive supervision in work organizations: Review, synthesis, and research agenda. Journal of Management, 33(3), 261-289. doi: $10.1177 / 0149206307300812$

Tepper, B. J., Carr, J. C., Breaux, D. M., Geider, S., Hu, C., \& Hua, W. (2009). Abusive supervision, intentions to quit, and employees' workplace deviance: A power/dependence analysis. Organizational Behavior and Human Decision Processes, 109(2), 156-167.

Tepper, B. J., Duffy, M. K., Hoobler, J., \& Ensley, M. D. (2004). Moderators of the relationships between coworkers' organizational citizenship behavior and fellow employees' attitudes. Journal of Applied Psychology, 89(3), 455. doi: 10.1037/00219010.89 .3 .455 
Tepper, B. J., Moss, S. E., Lockhart, D. E., \& Carr, J. C. (2007). Abusive supervison, upward maintenance communication, and subordinates' psychological distress. Academy of Management Journal, 50(5), 1169-1180. doi: 10.2307/20159918

Yuan, K.-H., \& Bentler, P. M. (2000). Three likelihood-based methods for mean and covariance structure analysis with nonnormal missing data. Sociological Methodology, 30(1), 165-200. doi: 10.1111/0081-1750.00078 
Table 1

Frequencies of Reported Forms of Abusive Supervision

Form of Abusive Supervision

\begin{tabular}{lccc}
\hline $\begin{array}{l}\text { Level of agreement with } \\
\text { exposure }\end{array}$ & Personal Attacks & Task Attacks & Isolation \\
\hline Strongly Agree & $14(1.4 \%)$ & $44(4.5 \%)$ & $6(1.2 \%)$ \\
Agree & $31(3.2 \%)$ & $115(11.7 \%)$ & $13(2.6 \%)$ \\
Slightly Agree & $65(6.6 \%)$ & $191(19.4 \%)$ & $48(9.8 \%)$ \\
Slightly Disagree & $88(8.9 \%)$ & $212(21.5 \%)$ & $60(12.2 \%)$ \\
Disagree & $358(36.4) \%$ & $281(28.6 \%)$ & $210(42.7 \%)$ \\
Strongly Disagree & $428(43.5 \%)$ & $141(14.3 \%)$ & $155(31.5 \%)$ \\
\end{tabular}


Table 2

Descriptive Statistics, Factor Loadings, Factor Errors, Correlation Coefficients and Cronbach Alpha Coefficients for the Study Variables

\begin{tabular}{lcccccccc}
\hline Variables & $\bar{x}$ & sd & 1 & 2 & 3 & 4 & 5 & 6 \\
\hline Abusive Supervision & & & & & & & \\
1.Task attack & 4.03 & 11.96 & $(.73)$ & & & & \\
2. Personal attack & 3.82 & 7.75 & $.57^{* *}$ & $(.87)$ & & & \\
3. Isolation & 2.08 & 4.26 & $.50^{* *}$ & $.71^{* *}$ & $\mathrm{NA}$ & & \\
Nurse consequences & & & & & & & & \\
4. Job Satisfaction & 4.04 & 23.10 & $-.36^{* *}$ & $-.13^{*}$ & -.01 & $(.86)$ & \\
5. Psychological Strain & 8.61 & 18.48 & $.43^{* *}$ & $.50^{* *}$ & $.46^{* *}$ & $-.25^{* *}$ & $(.94)$ \\
6. Intent to Quit & 6.35 & 19.54 & $.42^{* *}$ & $.35^{* *}$ & $.27^{* *}$ & $-.37^{* *}$ & $.38^{* *}$ & $(.73)$ \\
\end{tabular}

$* p<.05 . * * p<.01$. Note: The Cronbach alpha coefficients are on the diagonal. 


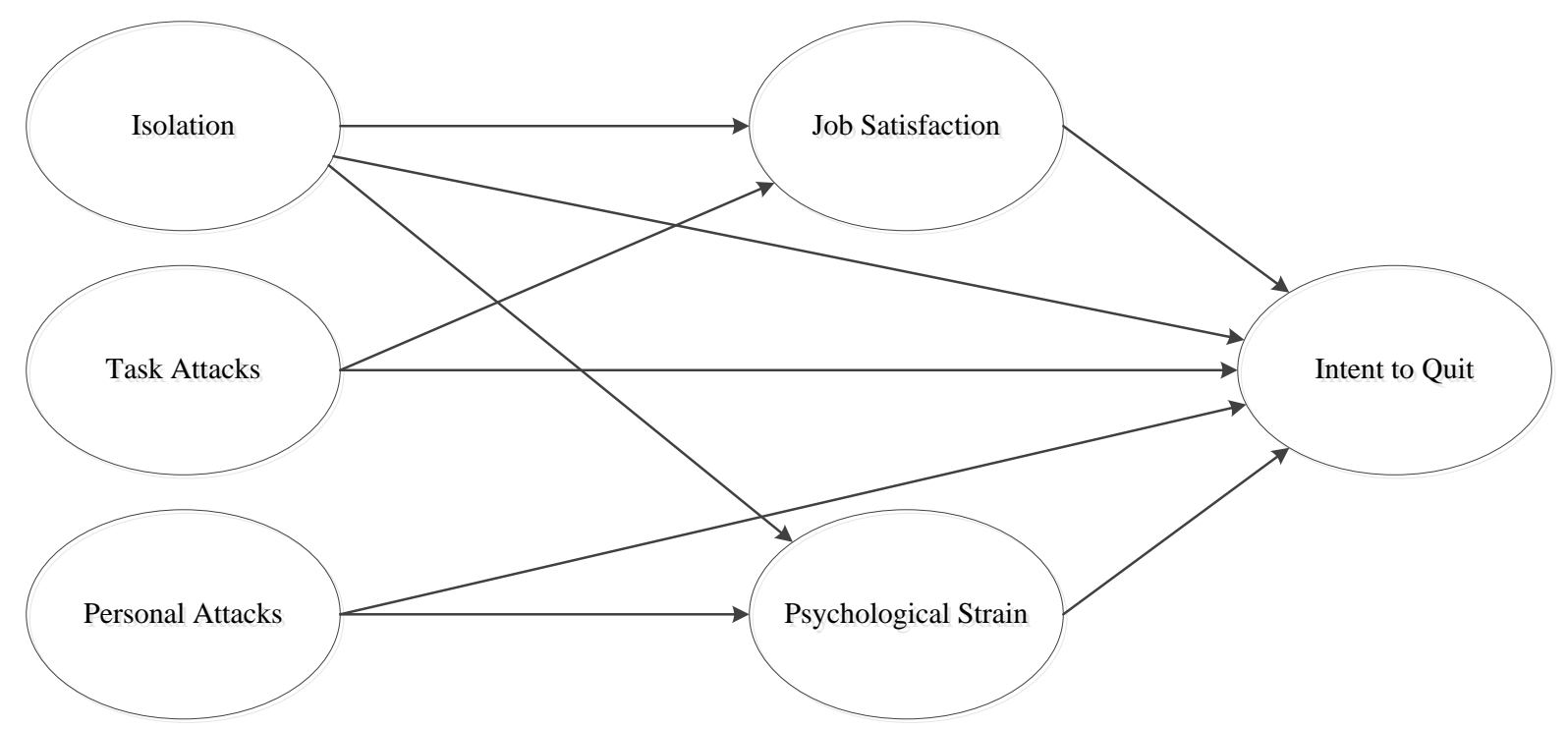

Figure 1. Hypothesised model $\left(\mathrm{M}_{1}\right)$

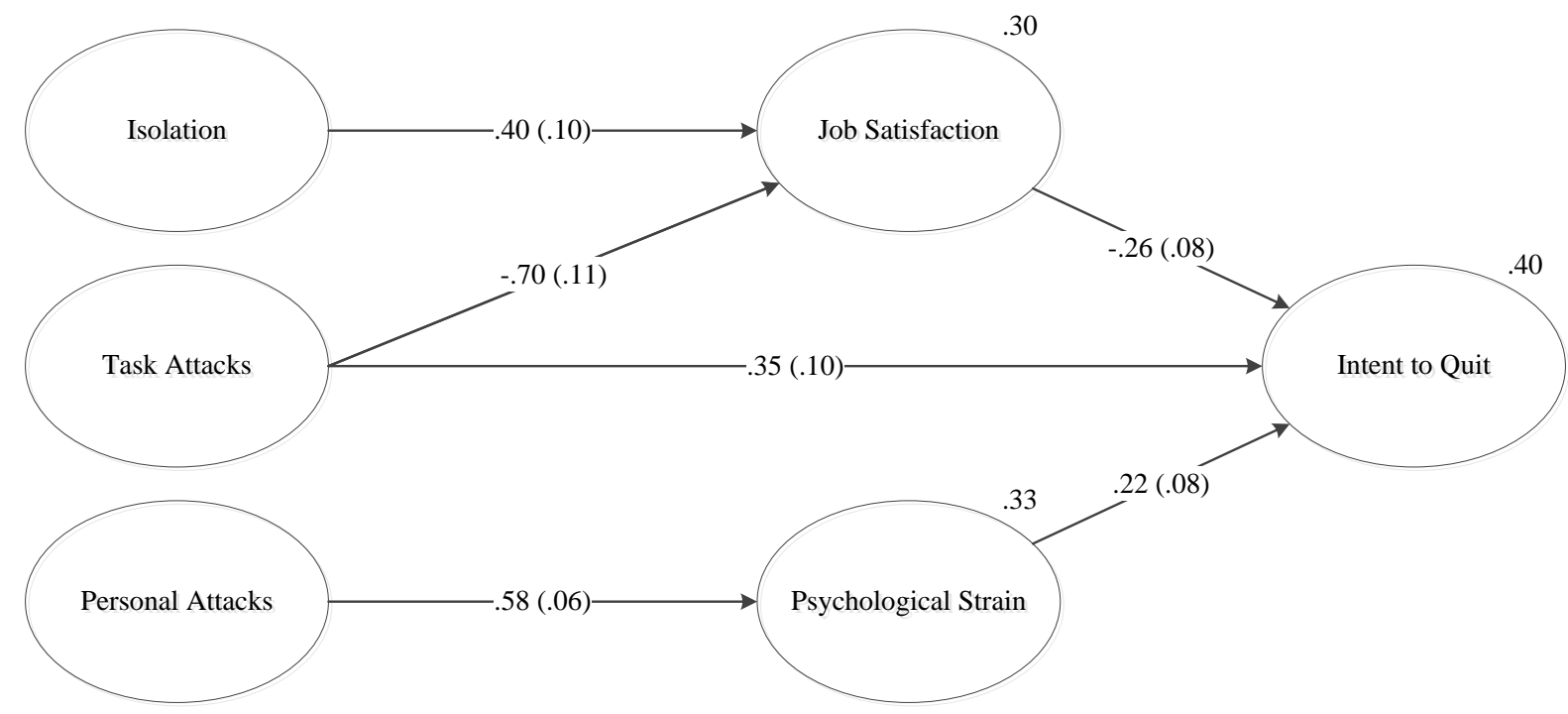

Figure 2. Model displaying significant relationships $\left(\mathrm{M}_{2}\right)$

Note. The $\mathrm{R}^{2}$ predicted (variance explained) for the variables are indicated in the figure above each variable. For example, .30 indicates that $30 \%$ of the variance for job satisfaction was explained. For clarity, the correlations between the variables are not presented in the figure. The standardised errors for each loading are provided in parentheses. 